ISAHP 2001, Berne, Switzerland, August 2-4, 2001

\title{
DETERMINING THE IMPORTANCE OF FISHERIES MANAGEMENT CRITERIA INCORPORATING INTEREST GROUP DIVERSITY ${ }^{1}$
}

\author{
Simon Mardle and Sean Pascoe \\ CEMARE, Dept. of Economics, University of Portsmouth, \\ Locksway Road, Portsmouth, Hants. PO4 8JF. UK. \\ (imon.mardle@port.ac.uk and sean.pascoe@port.ac.uk)
}

Keywords: analytic hierarchy process, weight aggregation, natural resources, fisheries, multiple interest groups.

\begin{abstract}
Summary: In determining the importance of criteria in the management of fisheries, two key issues stand out: that is the definition of a succinct list of criteria; and the determination of which interest groups play a defining role in the management development process. This is indeed the case for all natural resource management problems, and many other environmental problems as well. The analytic hierarchy process (AHP) provides an effective framework for the analysis required. This paper considers the development of a representative criteria hierarchy, and uses data obtained from a pairwise comparison survey based on a UK fishery to investigate the effectiveness of the procedure. Alternative approaches for the subproblem of measuring the importance of interest groups in the management structure are also considered.
\end{abstract}

\section{Extended Abstract}

In the field of natural resources, the problem of defining management strategies that are acceptable to all interest groups is an overriding aim. It is a feature that is apparent in many fields of study, but particularly noticeable in the natural resources due to the diversity of interests that exist. For example, typically workers, managers, politicians, environmentalists and scientists amongst others all have an acute interest. In situations where the industry does not impact heavily on the environment, then the conflict appears more limited. However, as in the field of fisheries management, where typically key stocks are considered to be over-fished, conflict between groups is heightened due to the sensitive nature of species protection versus the difficulties surrounding employment where there is significant intrinsic stochasticity in the system.

This paper attempts to analyze the effects of interest group activity in a specific case study of fisheries where this diversity of interest groups exists. The AHP (Saaty 1977 and 1980) provides an effective framework for the elicitation of preferences for management objectives in such a system. However, there are several subsequent options to analyze preference aggregation between interest groups within the management structure. Several methods have been suggested for the development and aggregation of group preferences, to measure the importance between groups. Ramanathan and Ganesh (1994) summarize the two main approaches and offer a general discussion on the two main methods of aggregation employed. These approaches treat the group as either a homogeneous or heterogeneous entity. The two basic aggregation methods applied to this are the geometric mean and (weighted) arithmetic mean. Articles by both Van Den Honert and Lootsma (1996) and Forman and Peniwati (1998) further develop the arguments introduced by Ramanathan and Ganesh (1994). Additionally, Forman and Peniwati (1998) discuss the use of these aggregation methods.

\footnotetext{
${ }^{1}$ This research is funded by the European Commission under a project entitled "Multiple Objectives in the Management of EU Fisheries" (5 ${ }^{\text {th }}$ framework project QLK5-1999-01273).
} 
Examples of studies where the AHP itself has been used to develop weights to measure the importance of groups in the management process are Ramanathan and Ganesh (1995) and Malczewski et al. (1997). The former study surveys individuals as an accompaniment to the elicitation of preferences in the main AHP survey. However, the latter study does not say whether a single decision-maker was chosen (termed a "supra decision maker" by Ramanathan and Ganesh, 1995) or a survey was undertaken for this.

This paper considers the development of a representative criteria hierarchy for the complex fisheries of the English Channel, and uses data obtained from a pairwise comparison survey to investigate the sensitivity of the procedure towards interest group preferences. Alternative approaches, with similar aims to those described above and others, for the sub-problem of measuring the importance of interest groups in the management structure are also considered and validated against known activity of the groups. The results show that such a framework of analysis offers useful information to the management process, potentially assisting in the definition of policy.

\section{References}

Forman, E. and Peniwati, K. (1998), “Aggregating individual judgments and priorities with the analytic hierarchy process”, European Journal of Operational Research, 108(1), 165-169.

Kangas, J. (1995), "Supporting the Choice of the Sports Fishing Site", Journal of Environmental Management, 43, 219-31.

Leung, P., Muraoka, J., Nakamoto, S.T. and Pooley, S. (1998), "Evaluating fisheries management options in Hawaii using analytic hierarchy process (AHP)", Fisheries Research, 36(2,3), 171-183.

Malczewski, J., Moreno-Sanchez, R., Bojorquez-Tapia, L.A. and Ongay-Delhumeau, E. (1997), "Multicriteria group decision-making model for environmental conflict analysis in the Cape Region, Mexico", Journal of Environmental Planning and Management, 40(3), 349-374.

Ramanathan, R and Ganesh, L.S. (1994), "Group preference aggregation methods employed in AHP: an evaluation and an intrinsic process for deriving members' weightages", European Journal of Operational Research, 79(20), 249-265.

Ramanathan, R. and Ganesh, L.S. (1995), "Energy resource allocation incorporating qualitative and quantitative criteria: an integrated model using GP and AHP”, Socio-Economic Planning Science, 29(3), 197-218.

Saaty, T.L. (1977), “A Scaling Method for Priorities in Hierarchical Structures”, Journal of Mathematical Psychology, 15(3), 234-281.

Saaty, T.L. (1980) The Analytic Hierarchy Process, New York: McGraw-Hill.

Van Den Honert, R.C. and Lootsma, F.A. (1996), "Group preference aggregation in the multiplicative AHP: the model of the group decision process and Pareto optimality", European Journal of Operational Research, 96, 363-370. 